\section{$\underset{\substack{\text { hommes } \\ \text { \& migrations }}}{ }$}

\section{Hommes \& migrations}

Revue française de référence sur les dynamiques

migratoires

$1296 \mid 2012$

Le Mexique dans les migrations internationales

\title{
Ouvrir une fenêtre sur le monde
}

\section{Marie Poinsot}

\section{(2) OpenEdition \\ Journals}

\section{Édition électronique}

URL : http://journals.openedition.org/hommesmigrations/1112

DOI : 10.4000/hommesmigrations. 1112

ISSN : 2262-3353

\section{Éditeur}

Musée national de l'histoire de l'immigration

\section{Édition imprimée}

Date de publication : 1 mars 2012

Pagination : 1

ISSN : 1142-852X

\section{Référence électronique}

Marie Poinsot, « Ouvrir une fenêtre sur le monde », Hommes \& migrations [En ligne], 1296 | 2012, mis en ligne le 29 mai 2013, consulté le 22 septembre 2020. URL : http://journals.openedition.org/

hommesmigrations/1112; DOI : https://doi.org/10.4000/hommesmigrations.1112 


\section{Ouvrir une fenêtre sur le monde

\author{
Par Marie Poinsot, rédactrice en chef
}

Les enjeux internationaux font partie des priorités éditoriales de Hommes \& Migrations. Plusieurs dossiers ont déjà abordé des problématiques internationales (diasporas arméniennes, nouvelles figures de l'immigration en Méditerranée, la Convention sur le droit des travailleurs migrants, migrations latino-américaines, mondialisation et migrations internationales, les migrations environnementales, etc.), ou mis l'accent sur des comparaisons bilatérales (France-Allemagne, France-Brésil, Algérie-France). À la lumière de l'étranger, qu'il soit européen ou mondial, ces mises en perspective permettent d'appréhender d'autres dynamiques migratoires, d'autres contextes sociopolitiques et économiques. Et d'analyser pourquoi la présence de populations migrantes engendre dans d'autres sociétés d'accueil des débats, des politiques publiques, des pratiques sociales, culturelles et artistiques qui sont différents selon les situations observées. Se dégagent des similarités que l'on pourrait qualifier de lois universelles des circulations humaines, mais aussi des divergences dues aux particularismes, aux histoires et aux modèles de société qui se structurent à l'échelle nationale, régionale ou parfois très localement. Avec le développement des routes migratoires, la revue privilégie des ères géographiques de plus en plus vastes, complétant par une approche géopolitique les autres disciplines des sciences sociales.

C'est pour répondre à ces enjeux que la rédaction a établi un contact continu avec les centres de recherches français à l'étranger. Une étude menée courant 2009 auprès d'une vingtaine de ces centres a permis d'identifier les travaux sur les phénomènes migratoires que la revue a proposé de publier pour les audiences francophones, favorisant des partenariats éditoriaux en réseau avec des institutions scientifiques en France ou à l'étranger. Nous souhaitons poursuivre cette démarche en ouvrant chaque année une nouvelle fenêtre sur le monde.

Pour ce numéro, le Centre d'études mexicaines et centraméricaines (Cemca) a coordonné un dossier à partir d'une sélection de contributions faites au colloque international «Le Mexique dans les migrations internationales, mises en perspective méditerranéennes » organisé à Marseille les 17-19 octobre 2011. La place du Mexique dans une dynamique migratoire globale y est abordée à travers une multitude de questionnements. Les articles explorent tous les aspects d'un pays d'émigration devenu depuis plusieurs décennies un pays de transit vers les États-Unis, principal pôle d'attraction des migrations. On sera surpris par les similitudes des situations analysées pour le Mexique avec celles de l'Europe méditerranéenne, justifiant un dialogue "Sud à Sud" propice à des échanges scientifiques entre chercheurs de ces deux aires territoriales. Les regards croisés vivifient les recherches et déterminent de nouvelles pistes. 